UDC 519.6

DOI: $10.22363 / 2312-9735-2017-25-4-373-379$

\title{
IVC Calculation Problem for Josephson Junction Stacks. On Asymptotic Construction near the Breakpoint
}

\section{S. I. Serdyukova}

\author{
Laboratory of Information Technologies \\ Joint Institute for Nuclear Research \\ 6 Joliot-Curie str., Dubna, Moscow region, 141980, Russian Federation
}

Solving the system of $n$ essentially nonlinear differential equations for different $I$ we obtain the current-voltage characteristics (IVC) for a system of $n$ Josephson junctions (JJ) as a hysteresis loop. When the current $I$ approaches on the back way the breakpoint $I_{b}$ the voltage $V(I)$ falls sharply to zero. In addition, in numerical modelling (non-periodic boundary conditions (NPBC)) IVC multiple branching is observed near $I_{b}$. It is interesting to study this phenomenon analytically developing asymptotic methods. There had been developed simple "asymptotic" formulas suitable for calculation of all IVC points except near to $I_{b}$. A numerical-analytical method allowing to shorten IVC calculation time essentially was proposed. This method showed good results in IVC multiple branching calculation in particular. All calculations were performed using the REDUCE system. We succeeded first to calculate analytically all points of IVC. An approximate solution at the breakpoint region (periodic boundary conditions (PBC)) has been developed using the Bogolyubov-Krylov method.

Key words and phrases: Josephson junctions, superconduction, high temperature, current-voltage characteristics, breakpoint, multiple branching, cross-scheme of the second order accuracy, asymptotic formulas developing, the Levinson method, the Bogolyubov-Krylov method, the REDUCE system

\section{Introduction}

The definition of the singular points of the current voltage characteristics together with the estimation of the width of their influence region provide adequate input for physical experiments aiming at studying the finite JJ stacks [1-3].

The mathematical problem of IVC calculation for the stack of $n$ Josephson junction [4] asks for the solution of the following essentially nonlinear system:

$$
\ddot{\varphi}_{l}=\sum_{l^{\prime}=1}^{n} A_{l, l^{\prime}}\left(I-\sin \left(\varphi_{l^{\prime}}\right)-\beta \dot{\varphi}_{l^{\prime}}\right), \quad l=1, \ldots, n .
$$

Here $\dot{\varphi}_{l}$ is derivative of $\varphi_{l}$ of $t, t \subset\left[0, T_{\max }\right]$.

Solving the Cauchy problem for different $I: I=I_{0}+k \Delta I \leqslant I_{\max }$ (right way) and $I=I_{\max }-k \Delta I$ we obtain IVC of $n$ Josephson junctions as hysteresis loop. The points $(I, V(I))$, with $I$ corresponding to the right way, form the right branch of the loop. And the points $(I, V(I))$, with $I$ corresponding to the back way, form the back branch of the loop. $V(I)$ is the total voltage of the stack.

For $I=I_{0}$ the system (1) is solved with zero initial data. For each next $I: I=I_{k+1}$, found $\varphi_{l}\left(I_{k}, T_{\max }\right), \dot{\varphi}_{l}\left(I_{k}, T_{\max }\right)$ are used as initial data.

The coefficients $A_{l, l^{\prime}}$ of the system (1) are elements of the matrix $A$. In the case of $\mathrm{PBC} A$ is symmetric square matrix of order $n$ :

Received $25^{\text {th }}$ July, 2017 . 


$$
\left(\begin{array}{cccccc}
1+2 \alpha & -\alpha & 0 & \ldots & 0 & -\alpha \\
-\alpha & 1+2 \alpha & -\alpha & 0 & \ldots & 0 \\
0 & -\alpha & 1+2 \alpha & -\alpha & 0 & \ldots \\
\ldots & \ldots & \ldots & \ldots & \ldots & \ldots \\
0 & \ldots & 0 & -\alpha & 1+2 \alpha & -\alpha \\
-\alpha & 0 & \ldots & 0 & -\alpha & 1+2 \alpha
\end{array}\right)
$$

And in the case of NPBC $A$ is symmetric square tridiagonal matrix of order $n$ :

$$
\left(\begin{array}{cccccc}
1+\alpha(1+\gamma) & -\alpha & 0 & \ldots & 0 & 0 \\
-\alpha & 1+2 \alpha & -\alpha & 0 & \ldots & 0 \\
0 & -\alpha & 1+2 \alpha & -\alpha & 0 & \ldots \\
\ldots & \ldots & \ldots & \cdots & \ldots & \ldots \\
0 & \ldots & 0 & -\alpha & 1+2 \alpha & -\alpha \\
0 & 0 & \ldots & 0 & -\alpha & 1+\alpha(1+\gamma)
\end{array}\right)
$$

The dynamics of phase differences $\phi_{l}(t)$ had been simulated [4] by solving the equation system (1) using the fourth order Runge-Kutta method. The aim was to shorten the time of IVC calculation, and it was achieved. First the number of the system equations was reduced to one in the case of PBC and halved in the case of NPBC. The longtime "asymptotics" formulas were developed. The mixed numerical-analytical method was suggested: all points of IVC are calculated using the asymptotics except points of the little arc of the back branch of the loop calculated numerically [5]. And Fig. 5 shows that the Runge-Kutta method of the fourth order accuracy can be replaced by the simplest explicit cross-scheme of the second order accuracy. This shortens the time of IVC calculation complimentarily.

\section{On Long-Time "Asymptotics" Construction}

In the case of PBC IVC calculation for a stack of $n$ intrinsic Josephson junctions is reduced to solving a unique equation [5]

$$
\ddot{\eta}(t)=-\beta \dot{\eta}(t)-\sin (\eta(t))+I .
$$

Solving this equation with given initial data $\eta(0)=d_{1}, \dot{\eta}(0)=d_{2}$ is equivalent to solving the following integral equation

$$
\eta(t)=\xi_{1}+\frac{\left(\xi_{2}-\omega\right)}{\beta}\left(1-e^{-\beta t}\right)+\omega t-\frac{1}{\beta} \int_{0}^{t}\left(1-e^{-\beta(t-s)}\right) \sin (\eta(s)) \mathrm{d} s .
$$

The simple iteration method starting from zero gives on the second step

$$
\eta_{2}=\omega t+A+\vartheta+\frac{\sin (\omega t+A+\operatorname{arctg}(\beta / \omega))}{\omega \sqrt{\beta^{2}+\omega^{2}}}+O\left(\omega^{-3}+e^{-\beta t}\right),
$$

where $\omega=I / \beta, A=d_{1}+\left(d_{2}-\omega\right) / \beta, \vartheta=-\cos (A) /(\omega \beta)$.

And the total voltage of the stack of $n$ Josephson junctions is calculated as

$$
V(I, n)=n \frac{\eta\left(I, T_{\max }\right)-\eta\left(I, T_{\min }\right)}{T_{\max }-T_{\min }} .
$$


In Fig. 1, Fig. 2, Fig. 3 the solid curve is the IVC back branch calculated using the Runge-Kutta method. In Fig. 1 the pictures of the back way of the hysteresis loop for 9 Josephson junctions are shown. The circles refer to "asymptotic" (using (5)) calculations respectively. Here we put $T_{\min }=50, T_{\max }=1000, \alpha=\beta=0.2, \Delta I=0.05$, the step in the Runge-Kutta method $h=0.1$.
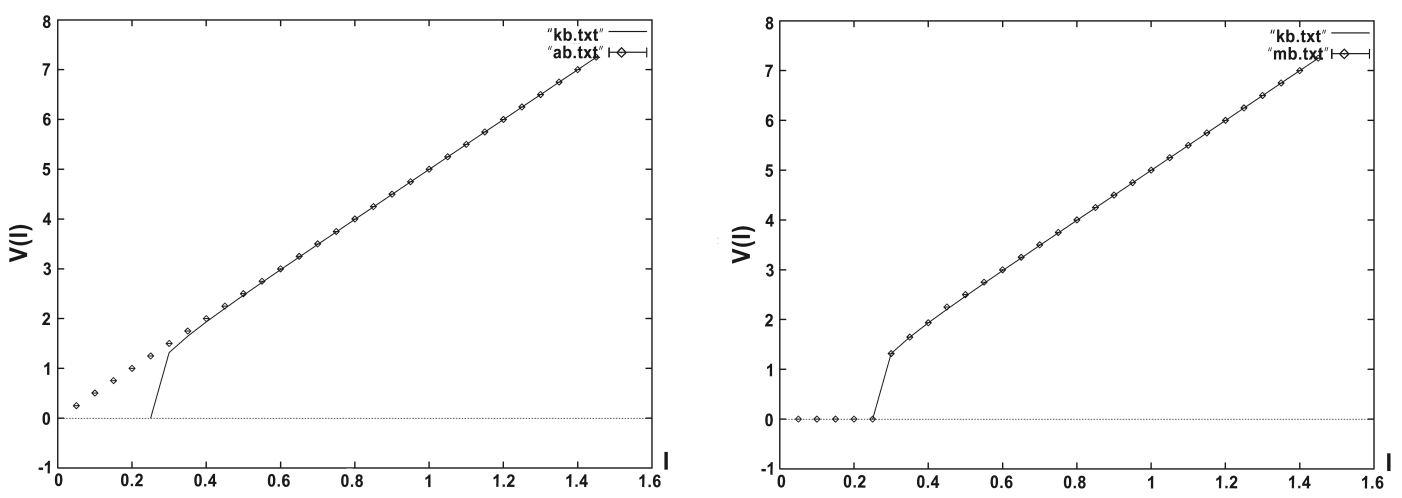

Figure 1. IVC back branch, $n=9$. PBC. Figure 2. IVC back branch, $n=9$. PBC. The circles were calculated using (5) numerical-analytical calculation

In Fig. 2 the circles refer to calculation performed by the following mixed analyticalnumerical method. The right branch of the hysteresis loop and the back branch on the interval $0.4<I<1.45$ were computed using (5). The rest ones were computed numerically. The REDUCE system [6] was used in all calculations performed.

We proved [7] that in the case of NPBC with $\gamma=1$ the problem of hysteresis loop calculation reduces to solving the following system of $n s$ integral equations:

$$
\begin{aligned}
\psi_{2 l-1}=\omega_{2 l-1} t+\xi_{1}(2 l-1) & +\frac{\xi_{2}(2 l-1)-\omega_{2 l-1}}{\beta \lambda_{2 l-1}}\left(1-\exp \left(-\beta \lambda_{2 l-1} t\right)\right)- \\
& -\frac{1}{\beta} \int_{0}^{t}\left(1-\exp \left(-\beta \lambda_{2 l-1}(t-s)\right)\right) \sum_{m=1}^{n} d_{m, 2 l-1} \sin \left(\varphi_{m}\right) \mathrm{d} s
\end{aligned}
$$

where

$$
\varphi_{m}=\sum_{k=1}^{n s} d_{m, 2 k-1} \psi_{2 k-1}, \quad l=1,2, \ldots, n s
$$

and $\omega_{2 l-1}=S_{2 l-1} I / \beta . \quad \lambda_{l}$ are eigenvalues of $A$ matrix, the corresponding eigenvectors are $E_{l}=\left[d_{1, l}, \ldots, d_{n, l}\right]^{*}, S_{l}=\sum_{k=1}^{n} d_{k, l}$. And $n s$ is integer part of $\frac{n+1}{2}, n s=\frac{n+1}{2}$.

The system (6) was solved using simple iterations starting at zero. The results obtained on the second step are regarded as long-time "asymptotics" of the system (6) solution.

We constructed "asymptotics" following to [8]. In the introduction N. Levinson declared: "A method is given for showing that formal "approximate solutions" of nonlinear differential equations are in fact the leading terms in an asymptotic representation of actual solutions".

The Fig. 3, Fig. 4 confirm this declaration. At the same time these pictures show efficiency of the suggested mixed numerical-analytical method. This time $\Delta I=0.001$. 
Fig. 3 refers to numerical calculation: all points of IVC were calculated using the RungeKutta method. Fig. 4 refers to calculation performed by the mixed numerical-analytical method: the right branch of IVC and the part of the back branch $(1.45 \geqslant I>0.4)$ were calculated analytically (using the long-time "asymptotics" of (6) system solution). The rest points $(0.4 \geqslant I \geqslant 0.2)$ were calculated numerically using the Runge-Kutta method.
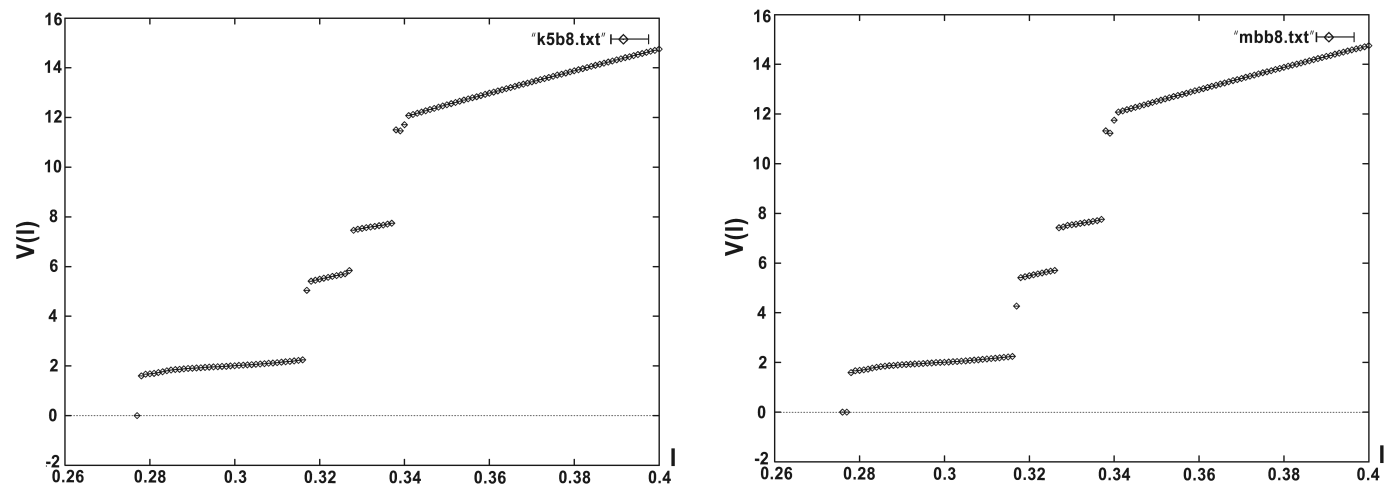

Figure 3. Multiple branching of IVC

Figure 4. Multiple branching of IVC back branch, $n=8$. NPBC. All points of back branch, $n=8$. NPBC. All points of IVC were calculated using the Runge-Kutta method IVC were calculated using "asymptotics" formulas except points of the interval on the picture calculated using the Runge-Kutta method
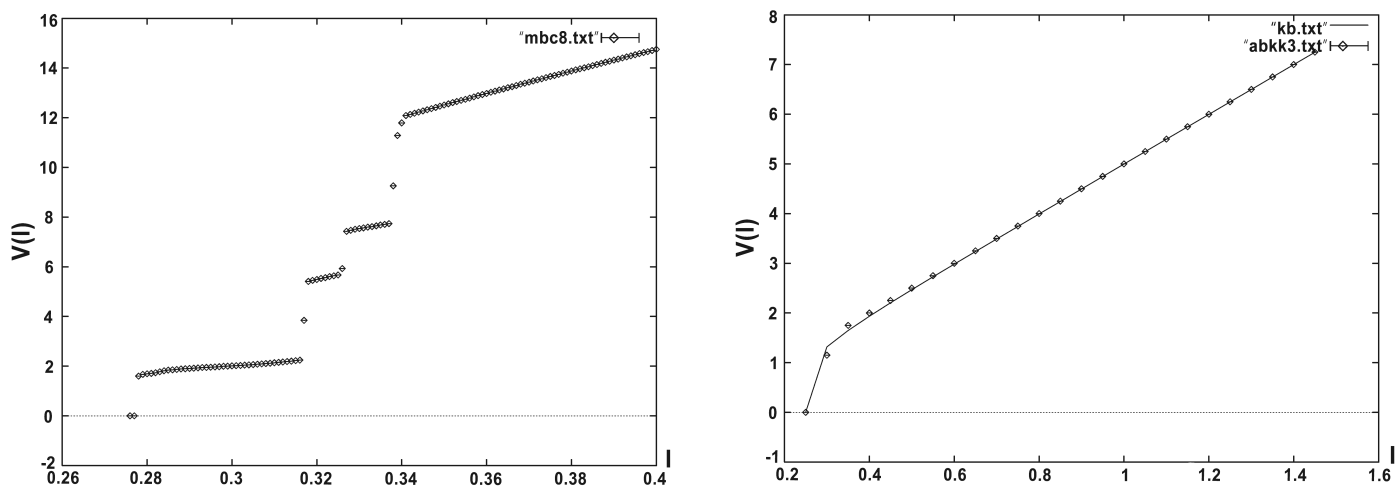

Figure 5. Multiple branching of IVC Figure 6. IVC back branch, $n=9$. PBC. back branch, $n=8$. NPBC. All points of In difference with Fig. 1 two circles IVC were calculated using $\quad(I=0.3, I=0.25)$ were calculated by $(7)$, "asymptotics" formulas except points of the interval on the picture calculated obtained by Bogolyubov-Krylov method using simplest cross-scheme of the second order accuracy

The Fig. 5 is similar to Fig. 4, but here the simplest explicit cross-scheme of the second order accuracy instead of the fourth order accuracy Runge-Kutta method was used. Remark that in both cases $\Delta t=0.1$ was chosen. 


\section{The Bogolyubov-Krylov Method Employment}

For studying multiple branching in current-voltage characteristics analytically we dream to prolong "asymptotics" till $\omega=1, I=0.2$. This moment we succeeded only to calculate analytically the whole hysteresis loop in the case of PBC. We developed approximate solution for the equation

$$
\ddot{\eta}(t)=-\beta \dot{\eta}(t)-\sin (\eta(t))+I
$$

with given initial data $\eta(0)=d_{1}, \dot{\eta}(0)=d_{2}$, in the case of small $\beta, I$, using the Bogolyubov-Krylov method [9]. We consider $\beta=0.2,0.2<I<0.4$. Let $\eta_{0}=\arcsin (I)$, $I=\sin \left(\eta_{0}\right)$,

$$
\sin (\eta)-I=\cos \left(\eta_{0}\right)\left(\eta-\eta_{0}\right)-\frac{\sin \left(\eta_{0}\right)}{2}\left(\eta-\eta_{0}\right)^{2}-\frac{\cos \left(\eta_{0}\right)}{6}\left(\eta-\eta_{0}\right)^{3}+\ldots
$$

New variable $\varphi=\eta-\eta_{0}$ satisfying equation

$$
\ddot{\varphi}=-\beta \dot{\varphi}-\cos \left(\eta_{0}\right) \varphi+\frac{\sin \left(\eta_{0}\right)}{2} \varphi^{2}+\frac{\cos \left(\eta_{0}\right)}{6} \varphi^{3},
$$

which can be rewritten as

$$
\ddot{\varphi}+\beta \dot{\varphi}+\omega^{2}\left(\varphi-\frac{\varphi^{3}}{6}-\operatorname{tg}\left(\eta_{0}\right) \frac{\varphi^{2}}{2}\right)=0, \quad \ddot{\varphi}+\omega^{2} \varphi=\beta f(\varphi, \dot{\varphi}),
$$

$\omega^{2}=\cos \left(\eta_{0}\right)=\left(1-I^{2}\right)^{1 / 4}$. This equation has solution $\varphi=a \cos (\psi), \dot{\varphi}=-a \omega \sin (\psi)$, $\psi=\omega t+\vartheta$, where $a$ and $\psi$ are determined by the first approximation equations

$$
\frac{\mathrm{d} a}{\mathrm{~d} t}=-\frac{\beta}{2} a, \quad \frac{\mathrm{d} \psi}{\mathrm{d} t}=\omega\left(1-\frac{a^{2}}{16}\right) .
$$

Following step by step to [9], we obtain

$$
\begin{gathered}
a=a_{0} \exp (-\beta t / 2), \quad \psi=\omega\left(t+\frac{a_{0}^{2}}{16 \beta}(\exp (-\beta t)-1)+\vartheta,\right. \\
\eta=\eta_{0}+a_{0} \exp (-\beta t / 2) \cos \left(\omega\left(t+\frac{a_{0}^{2}(\exp (-\beta t)-1)}{16 \beta}\right)+\vartheta\right),
\end{gathered}
$$

$a_{0}$ and $\vartheta$ are determined by given initial data:

$$
d_{1}=\eta_{0}+a_{0} \cos (\vartheta), \quad d_{2}=-a_{0} \beta / 2-a_{0} \omega\left(1-a_{0}^{2} / 16\right) \sin (\vartheta) .
$$

Let $x=a_{0} \cos (\vartheta), y=a_{0} \sin (\vartheta), a_{0}^{2}=x^{2}+y^{2}$, the first equation of (5) gives $x=$ $d_{1}-\eta_{0}$, and $y$ is determined of the third order polynomial equation

$$
d_{2}+\beta\left(d_{1}-\eta_{0}\right) / 2+\omega y\left(1-\left(\left(d_{1}-\eta_{0}\right)^{2}+y^{2}\right) / 16\right)=0 .
$$

This equation has at least one real root. When $x, y$ are found, $a_{0}=\sqrt{x^{2}+y^{2}}$ and $\vartheta=\arcsin \left(y / a_{0}\right)$. By such a way we could correct Fig. 1. In Fig. 6 the back branches of the hysteresis loop for the case of PBC are presented.

The solid curve is the same as in Fig. 1. The circles on the solid curve were found analytically using mixed analytical method: all points of the hysteresis loop were calculated using $(5)$ - except two points $(I=0.3,0.25)$ calculated using $(7)$. 


\title{
References
}

1. H. H. Zappe, Minimum Current and Related Topics in Josephson Tunnel Junction Devices, Journal of Applied Physics 44 (3) (1973) 1371-1377.

2. Y. Matsuda, M. B. Gaifullin, K. Kumagai, et al., Collective Josephson Plasma Resonance in the Vortex State of $\mathrm{Bi}_{2} \mathrm{Sr}_{2} \mathrm{CaCu}_{2} \mathrm{O}_{8+\delta}$, Physical Review Letters 75 (24) (1995) 4512-4515.

3. M. Machida, T. Koyama, M. Tachiki, Dynamical Breaking of Charge Neutrality in Intrinsic Josephson Junctions: Common Origin for Microwave Resonant Absorptions and Multiple-Branch Structures in I-V Characteristics, Physical Review Letters 83 (22) (1999) 4618-4621.

4. Yu. M. Shukrinov, F. Mahfouzi, N. F. Pedersen, Investigation of the Breakpoint Region in Stacks with a Finite Number of Intrinsic Josephson Junctions, Physical Review B 75 (10) (2007) 104508.

5. S. I. Serdyukova, Numerical-Analytical Method for Computing the Current-Voltage Characteristics for a Stack of Josephson Junctions, Computational Mathematics and Mathematical Physics 52 (11) (2012) 1590-1596.

6. W. Neun, REDUCE User's Guide for Unix Systems. Version 3.8 (2004). URL http://sid.ethz.ch/debian/reduce/reduce-algebra-0+20110221/psl/ unix-oper.pdf

7. S. I. Serdyukova, Determination of IVC Breakpoint for Josephson Junction Stack. Non-Periodic Boundary Conditions with $\gamma=1$, Particles and Nuclei, Letters 11 (4) (2014) 784-795.

8. N. Levinson, Asymptotic Behavior of Solutions of Non-linear Differential Equations, Studies in Applied Mathematics 48 (4) (1969) 285-297.

9. N. N. Bogolyubov, Yu. A. Mitropolskiy, Asymptotic Methods in the Theory of Nonlinear Oscillations, Fizmatlit, Moscow, 1963, in Russian.

УДК 519.6

DOI: $10.22363 / 2312-9735-2017-25-4-373-379$

\section{Вычисление ВАХ для систем джозефсоновских переходов. О построении асимптотики вблизи точки излома}

\section{С. И. Сердюкова}

\author{
Лаборатория информационных технологий \\ Обгединённый институт ядерных исследований \\ ул. Жолио-Кюри, д. 6, Дубна, Московская область, Россия, 141980
}

Решая систему $n$ существенно нелинейных дифференциальных уравнений, мы получаем вольт-амперную характеристику (BAX) для системы $n$ джозефсоновских переходов (JJ) в виде петли гистерезиса. На обратном пути при подходе к точке излома $I_{b}$ напряжение $V(I)$ резко спадает к нулю. Кроме того, при численном моделировании (случай непериодических граничных условий) ВАХ в окрестности точки излома наблюдается множественное ветвление ВАХ вблизи точки $I_{b}$. Интересно исследовать это явление аналитически, развивая асимптотические методы. Удалось построить простые «асимптотические» формулы, пригодные для вычисления всех точек BAX, кроме близких к $I_{b}$. Был предложен численно аналитический метод, позволивший существенно сократить время вычисления BAX. Этот метод показал хорошие результаты в частности при вычислении множественных ветвлений BAX. Система REDUCE использовалась во всех проведённых расчётах Впервые удалось вычислить аналитически все точки петли гистерезиса. Приближенное решение в окрестности точки излома (случай периодических граничных условий) построено по методу Боголюбова-Крылова.

Ключевые слова: джозефсоновские переходы, сверхпроводимость, высокие температуры, вольт-амперные характеристики, точка излома, множественные ветвления, схема-крест второго порядка точности, вывод асимптотических формул, метод Левинсона, метод Боголюбова-Крылова, система REDUCE 


\section{Литература}

1. Zappe H. H. Minimum Current and Related Topics in Josephson Tunnel Junction Devices // Journal of Applied Physics. - 1973. — Vol. 44, No 3. — Pp. 1371-1377.

2. Collective Josephson Plasma Resonance in the Vortex State of $\mathrm{Bi}_{2} \mathrm{Sr}_{2} \mathrm{CaCu}_{2} \mathrm{O}_{8+\delta} /$ Y. Matsuda, M. B. Gaifullin, K. Kumagai et al. // Physical Review Letters. - 1995. Vol. 75, No 24. - Pp. 4512-4515.

3. Machida M., Koyama T., Tachiki M. Dynamical Breaking of Charge Neutrality in Intrinsic Josephson Junctions: Common Origin for Microwave Resonant Absorptions and Multiple-Branch Structures in I-V Characteristics // Physical Review Letters. 1999. - Vol. 83, No 22. - Pp. 4618-4621.

4. Shukrinov Yu. M., Mahfouzi F., Pedersen N. F. Investigation of the Breakpoint Region in Stacks with a Finite Number of Intrinsic Josephson Junctions // Physical Review B. - 2007. - Vol. 75, No 10. - P. 104508.

5. Serdyukova S. I. Numerical-Analytical Method for Computing the Current-Voltage Characteristics for a Stack of Josephson Junctions // Computational Mathematics and Mathematical Physics. — 2012. — Vol. 52, No 11. — Pp. 1590-1596.

6. Neun W. REDUCE User's Guide for Unix Systems. Version 3.8. - 2004. — http:// sid.ethz.ch/debian/reduce/reduce-algebra-0+20110221/psl/unix-oper.pdf.

7. Serdyukova $S$. I. Determination of IVC Breakpoint for Josephson Junction Stack. NonPeriodic Boundary Conditions with $\gamma=1 / /$ Particles and Nuclei, Letters. - 2014. Vol. 11, No 4. - Pp. 784-795.

8. Levinson N. Asymptotic Behavior of Solutions of Non-linear Differential Equations // Studies in Applied Mathematics. - 1969. - Vol. 48, No 4. - Pp. 285-297.

9. Боголюбов H. Н., Митропольский Ю. А. Асимптотические методы в теории нелинейных колебаний. - М.: Физматлит, 1963.

(C) Serdyukova S.I., 2017

Для цитирования:

Serdyukova S.I. IVC Calculation Problem for Josephson Junction Stacks. On Asymptotic Construction near the Breakpoint // RUDN Journal of Mathematics, Information Sciences and Physics. - 2017. - Vol. 25, No 4. - Pp. 373-379. - DOI: 10.22363/2312-9735-2017-25-4-373-379.

\section{For citation:}

Serdyukova S.I. IVC Calculation Problem for Josephson Junction Stacks. On Asymptotic Construction near the Breakpoint, RUDN Journal of Mathematics, Information Sciences and Physics 25 (4) (2017) 373-379. DOI: 10.22363/2312-97352017-25-4-373-379.

Сведения об авторах:

Сердюкова Светлана Ивановна - профессор, доктор физико-математических наук, ведущий научный сотрудник научного отдела вычислительной физики лаборатории информационных технологий Объединённого института ядерных исследований, г. Дубна (e-mail: sis@jinr.ru, тел.: +7 (49621) 64731)

\section{Information about the authors:}

Serdyukova S. I. - professor, Doctor of Physical and Mathematical Sciences, leading researcher of Scientific Department of Computational Physics of Information Technology Laboratory of Joint Institute for Nuclear Research, Dubna (e-mail: sis@jinr.ru, phone: +7 (49621) 64731) 